\title{
A Computational Procedure for an Expanded Steiner-Weber Problem of Optimal Location
}

\author{
Abbas Mirakhor and Charles D. BennetT*
}

INTRODUCTION

The purpose of this note is to present a realistic approximation to the classical Steiner-Weber minimization problem for optimally locating a central facility by first constructing a continuous model employing population regions and second using a centroidal approach to aid in the solution of the regional location problem. The problem under consideration can basically be stated as follows:

Consider the problem of optimally locating a central facility serving a community consisting of a large number of persons who will be using the facility. Constructing a Cartesian coordinate system over the feasible community area and employing Euclidean measure of effectiveness in analyzing the problem, the central facility would be located where the sum of the distances from the central facility to each person in the community who will use the facility (weighted by some factors to allow for differences in trip frequency, cost per trip, etc.) was at a minimum.

Mathematically, the problem can be stated

$$
\underset{\mathrm{x}, \mathrm{y}}{\operatorname{Min}} \underset{\mathrm{i}=1}{\mathrm{n}} \mathrm{w}_{\mathrm{i}}\left[\left(\mathrm{x}-\mathrm{x}_{\mathrm{i}}\right)^{2}+\left(\mathrm{y}-\mathrm{y}_{\mathrm{i}}\right)^{2}\right]^{1 / 2}
$$

where $x_{i}, y_{i}$ and $w_{i}$ are, respectively, the $x$-coordinate of the location of the residence of the ith person, the y-coordinate of the location of the ith person, and the product of the weighting factors for the ith person.

Equation (1) could be used as a measure of effectiveness only if all the elements of the sum were known, i.e., the location and weights for each person in the community. This information may not be known and the difficulty in obtaining it may prove prohibitive.

A high degree of realism could be maintained if the community comprising the residences concerned were viewed as a continuous area and sectioned into regions, each with some common characteristics, such as trip frequency, travel costs per trip, and population density. The resulting aerial location problem will still attempt to minimize the sum of the Euclidean distances from the central ville.

*Associate Professor of Economics and graduate student respectively, University of Alabama in Hunts- 
facility location to each person on the ith population region. Only now equation (1) becomes

$$
\underset{\mathrm{x}, \mathrm{y}}{\operatorname{Min}} \underset{\mathrm{i}=1}{\mathrm{~m}} \iint_{\mathrm{R}_{\mathrm{i}}} \mathrm{w}_{\mathrm{i}}\left[\left(\mathrm{x}-\mathrm{x}_{\mathrm{i}}\right)^{2}+\left(\mathrm{y}-\mathrm{y}_{\mathrm{i}}\right)^{2}\right]^{1 / 2} \mathrm{dydx}
$$

where $R_{i}$ represents the aerial dimensions of the ith region, $i=1,2, \ldots, m ; w_{i}$ is the product of the weighting factors for the ith region; $\mathrm{x}, \mathrm{y}$ are the coordinates of feasible location for the central facility; and $\bar{x}_{i}, y_{i}$ are the coordinates of the persons comprising the ith population region [9].

Each element of the sum of equation (2) involves the evaluation of a double integral, integrated over the limits of the ith region for each of the $\mathrm{m}$ regions. The evaluation of equation (2) involves a somewhat prohibitive degree of complexity except in the case where the region is restricted to be rectangular in shape and of uniform population density. Even in this restricted case, though, the computational time needed to implement a computer searching procedure, as well as other shortcomings, leads us to look for an alternative measure of effectiveness on which to base the search.

The solution of the problem stated by equation (2) has been approached by Love [9] by restricting his analysis to only those cases where the population regions are rectangular (or can be approximated by a series of rectangles) and have a uniformly distributed population density. To solve the problem for this restricted case, a general mathematical expression is derived for each element in the sum of equation (2), i.e., each double integral, which is then coupled with a computer searching technique [3,4] to locate both an unconstrained and constrained optimum location. The shortcomings of using this method for those cases where Love's model is applicable are three-fold.

First, the complexity of the final expression for the solution of each double integral of equation (2) requires both unnecessary time in its evaluation and numerical approximation methods in any gradient searching procedure which might use the expression, thus reducing the efficiency of the gradient method and increasing computation time. Second, the realism of the model is limited by the necessity of rectangular regions. Irregular shaped regions may be sub-divided into small rectangles as an approximation, but another element of the sum of equation (2) is added and another evaluation of a double integral is required, increasing computation time even further. Thirdly, population density differences among regions are used as part of the constant multiplier $\mathrm{w}_{\mathrm{i}}$, so there is a need for the assumption of a constant population density within a region. This is a rather unrealistic assumption unless the population regions are specified as relatively small areas, which forces the limit of the sum (m) in equation (2) to increase for a given community size. Thus, equation (2) will involve more double integrals to be evaluated and computation time will increase.

\section{The Location Model}

An alternative to evaluating equation (2) is the consideration of using the sum of the distances between the central facility location and the centroids of 
the population regions as a measure of effectiveness to be minimized. Mathematically the objective function would then become

$$
\operatorname{Min}_{\mathrm{x}, \mathrm{y}} \underset{\mathrm{i}=1}{\mathrm{~m}} \mathrm{w}_{\mathrm{i}}\left[\left(\mathrm{x}-\overline{\mathrm{x}}_{\mathrm{i}}\right)^{2}+\left(\mathrm{y}-\overline{\mathrm{y}}_{\mathrm{i}}\right)^{2}\right]^{1 / 2}
$$

where $\bar{x}_{i}$ and $\bar{y}_{i}$ are, respectively, the $\mathrm{x}$ and $\mathrm{y}$ components of the centroid of the ith region and the multiplier $\mathrm{w}_{\mathrm{i}}$ contains a new factor, that of the area of the ith region. Notice that the Steiner-Weber problem of equation (1), the original objective function, was approximated by equation (2), an aerial problem involving difficulties in its solution. Equation (2) can be reduced to equation (3), another Steiner-Weber problem because of the fact that the optimal facility location $x^{*}, y^{*}$ obtained from using equation (2) as a measure of effectiveness coincides with the optimal facility location obtained by using equation (3).

The evaluation of each element of the sum of equation (3) involves only the calculation of the centroid of the ith region and the area of the ith region. The, $\mathrm{x}$ and $\mathrm{y}$ coordinates of the centroid of each region are known to be the first moment of the area about the appropriate axis divided by the area of the region, i.e.,

$$
\bar{x}_{i}=\frac{\iint R_{i}{ }^{x} \delta_{i}(x, y) d y d x}{\iint R_{i}{ }^{\delta_{i}}(x, y) d y d x}
$$

and

$$
\overline{\mathrm{y}}_{\mathrm{i}}=\frac{\iint \mathrm{R}_{\mathrm{i}}{ }^{\mathrm{y} \delta_{\mathrm{i}}}(\mathrm{x}, \mathrm{y}) \mathrm{dydx}}{\iint \mathrm{R}_{\mathrm{i}}{ }^{\delta_{\mathrm{i}}}(\mathrm{x}, \mathrm{y}) \mathrm{dydx}}
$$

where $\delta \mathrm{i}(\mathrm{x}, \mathrm{y})$ is the density function of the ith population region, relating population density to the $x, y$ coordinates within a region.

Thus, equations (4) and (5) are used to calculate $\left(\overline{\mathrm{x}}_{\mathrm{i}}, \overline{\mathrm{y}}_{\mathrm{i}}\right), \mathrm{i}=1,2, \ldots, \mathrm{m}$ and equation (3) provides the measure of effectiveness to be used with one of the many solution techniques of the Steiner-Weber problem $[5,10]$.

\section{Numerical Example}

Consider the community as portrayed by Figure 1 showing a community consisting of seven regions, each with different dimensions and population densities. The coordinates of the actual persons whose residences comprise the regions are not known. For this reason, if a commonly used facility were to be located at some location to serve the community, equation (1) could not be used. However, if the dimensions of each region are known, as is the case here, equation (2) can provide the necessary approximation of equation (1), and equation (3) can be used as a measure of effectiveness in the search. 


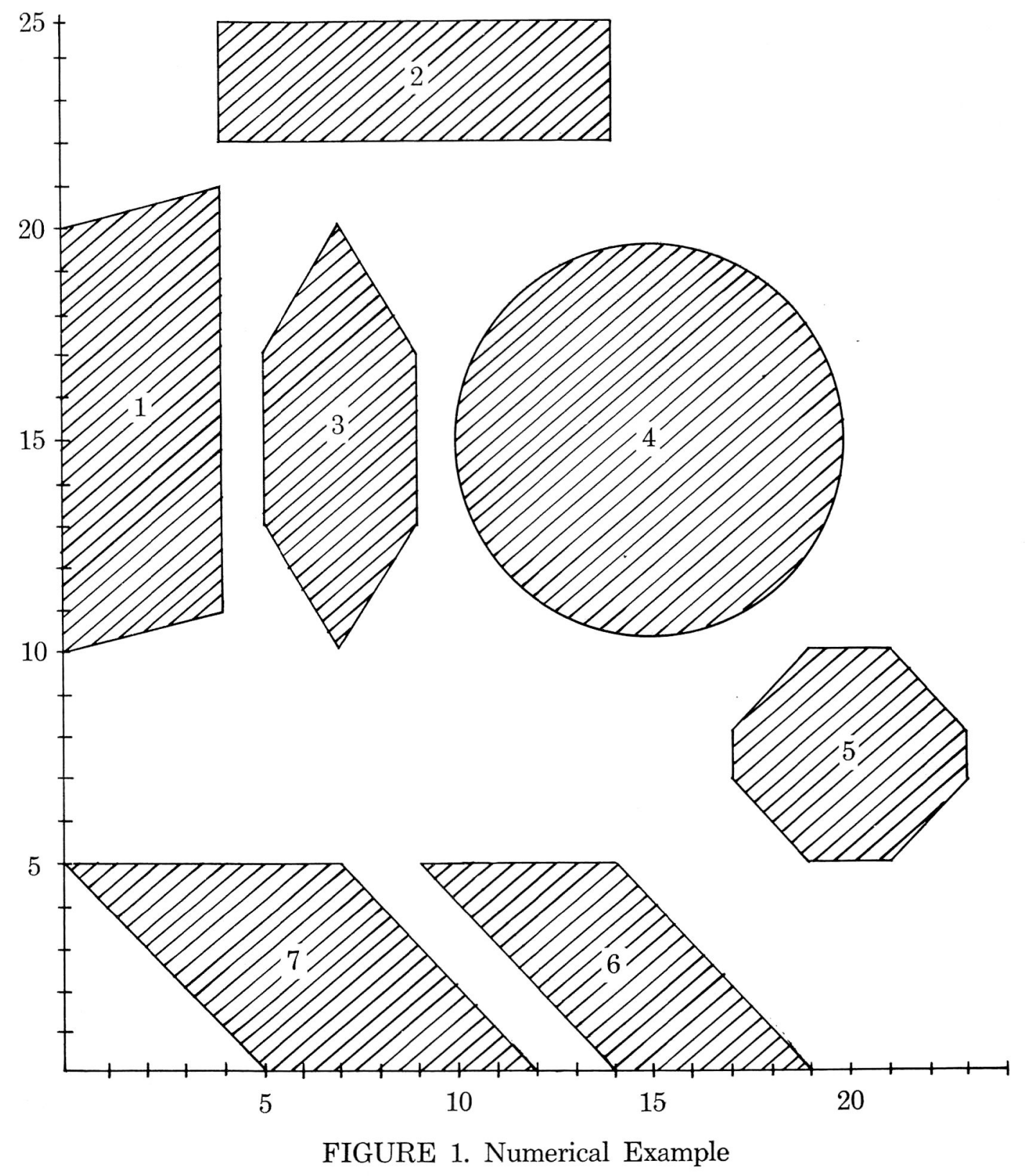


The $\mathrm{x}$ and $\mathrm{y}$ coordinates of the centroids of the ith region along with the area of the ith region are found using equations (4) and (5). The resulting centroid coordinates $\left(\overline{\mathrm{x}}_{i}, \overline{\mathrm{y}}_{\mathrm{i}}\right)$, the regional area $\left(\mathrm{A}_{\mathrm{i}}\right)$, the travel cost per trip $\left(c_{i}\right)$, the trip frequency referenced over some common time period $\left(\mathrm{f}_{\mathrm{i}}\right)$, and the population density $\left(d_{i}\right)$ for each of the seven population regions are shown in Table 1.

Mathematically, then, the problem at hand is

$$
\underset{x, y}{\operatorname{Min}} \sum_{i=1}^{7} c_{i} \cdot f_{i} \cdot d_{i} \cdot A_{i} \cdot\left[\left(x-\bar{x}_{i}\right)^{2}+\left(y-\bar{y}_{i}\right)^{2}\right]^{1 / 2}
$$

where the parameters $c_{i}, f_{i}, d_{i}$, and $A_{i}$ are specified in Table 1.

The problem is convex [9] and Carroll's Created Response Surface Technique [3] employing Fiacco and McCormick's SUMT algorithm [4] was programmed [1] and utilized in solving the above problem. ${ }^{1}$

Computational results are shown in Table 2.

\section{Conclusions}

The above centroidal model used with Fiacco and McCormick's SUMT searching algorithm provides an efficient and realistic solution to the minimization problems of equations (2) and (3). When data is not available to use equa-

Table 1. Parameters for Numerical Example

\begin{tabular}{rrrllll}
\hline $\mathrm{i}$ & \multicolumn{1}{c}{$\mathrm{x}_{\mathrm{i}}$} & \multicolumn{1}{c}{$\mathrm{y}_{\mathrm{i}}$} & $\mathrm{A}_{\mathrm{i}}$ & $\mathrm{c}_{\mathbf{i}_{\mathbf{i}}}$ & $\mathrm{f}$ & $\mathrm{d}_{\mathrm{i}}$ \\
\hline 1 & 2.0 & 15.5 & 50 & 1.0 & 1 & 1 \\
2 & 9.0 & 23.5 & 30 & 1.5 & 5 & 1 \\
3 & 15.0 & 6.5 & 21 & 1.3 & 3 & 1 \\
4 & 14.0 & 15.0 & 78.5 & 1.1 & 2 & 1 \\
5 & 20.0 & 7.5 & 22 & 2.0 & 1 & 1 \\
6 & 14.0 & 2.5 & 25 & 3.1 & 4 & 1 \\
7 & 6.0 & 2.5 & 35 & 2.8 & 2 & 1 \\
\hline
\end{tabular}

Table 2. Computational Results

Total Elapsed Time CPU Time Optimum $x^{*}, y^{*}$


tion (1) as a measure of effectiveness, the problem can be approximated with equation (2) and the centroidal model utilized for its solution with good results.

It must be noted that the total cost of transportation incurred by the community by locating the central facility at $\mathrm{x}^{*}, \mathrm{y}^{*}$ is never known using the centroidal approach, but we do know that this total cost is at a minimum at this location.

In the sample problem shown here, each of the seven population regions were of different shapes, had different areas, different trip frequencies and different cost factors. The population density within a region, though, was constant. Equations (4) and (5) free us from this necessity in that a density function may be specified, i.e., $\delta_{i}(x, y), i=1,2, \ldots, n$, relating population density within the ith population region to the $\mathrm{x}, \mathrm{y}$ coordinates. This density function would become part of the numerator and denominator of equations (4) and (5) and the resulting centroid would account for the variance of population density within the region. In this case, the multiplier $d_{i}$ for the ith region would assume the average population density value in that region, all other multipliers for that region remaining unchanged. This average value of the population density for the ith region may be found by substituting the $\mathrm{x}, \mathrm{y}$ coordinate of the centroid, $\overline{\mathrm{x}}_{\mathrm{i}}, \overline{\mathrm{y}}_{\mathrm{i}}, \overline{\text { into }}_{\mathrm{i}}$ the density function $\delta \mathrm{i}(\mathrm{x}, \mathrm{y})$.

In the cases where the density within a region is constant, i.e., $\delta \mathrm{i}(\mathrm{x}, \mathrm{y})=\delta \mathrm{i}$, the density cancels in equations (4) and (5) and the centroid is irrespective of the density.

\section{FOOTNOTES}

1Computer programmed in FORTRAN IV and run utilizing UNIVAC 1108 at University of Alabama in Huntsville Research Institute.

\section{REFERENCES}

1. Barclay, D., H. Stern and D. Strimling, "A Version of Fiacco and McCormick's Sequential Unconstrained Minimization Technique (SUMT)," Unpublished Paper, University of Alabama in Huntsville, Huntsville, Alabama.

2. Cabot, A. V., R. L. Francis and M. A. Story, "A Network Flow Solution to A Rectilinear Distance Facility Location Problem," AIIE Transactions, 16 (1970), 132-141.

3. Carroll, C. W., "The Created Response Surface Technique for Optimizing Non-Linear Restrained Systems," Operations Research, 9 (1961), 169-184.

4. Fiacco, A. V. and G. P. McCormick, "Computational Algorithm for the Sequential Unconstrained Minimization Technique for Non-Linear Programming," Management Science, 10 (1964), 601-617.

5. Francis, R. L. and J. A. White, Facility Layout and Location: An Analytical Approach, Chapter 4, Currently in Process of Printing, Prentice-Hall Publ., 1973.

6. Kuhn, H. W., "Locational Problems and Mathematical Programming," Separatum-Colloquium on the Application of Mathematics to Economics, Budapest, 1963. Publishing House of the Hungarian Academy of Sciences, Budapest, 1965.

7. “ “On a Pair of Duel Non-Linear Problems," Non-Linear Programming, Chapter 3, Abadie, editor, John Wiley and Sons, Inc., New York, New York, 1967.

8. and R. E. Kuenne, "An Efficient Algorithm for the Numerical Solution of the Generalized Weber Problem in Spatial Economics," Journal of Regional Science, 4 (1962), 21-33.

9. Love, R. F., "A Computational Procedure for Optimally Locating a Facility with Respect to Several Rectangular Regions,” Journal of Regional Science, 12 (1972), 233-242.

10. Nobel, B., "Optimum Location Problems," Applications of Undergraduate Mathematics in Engineering, Chap. 2, The McMillan Company, New York, New York, 1967.

11. Thomas, G. B., "Physical Allocations," Calculus, Chap. 13, Addison-Wesley Publishing Company, Reading, Massachusetts. 